\title{
Psychotherapeutische diagnostiek
}

Naar een constructieve alliantie

Paul van der Heijden, Jan Derksen en Jos Egger

'Echte' psychotherapeuten testen niet. Zo is het al heel lang. Toch worden ze wel geacht psychodiagnostiek te bedrijven. Zij doen dat hoofdzakelijk met twee databronnen in plaats van met drie: kijken en praten. Hun testvaardigheden zijn verouderd, versleten of anderszins achteruitgegaan. Zij lopen, zeker bij complexe stoornissen, uit de pas met de tegenwoordige richtlijnen (Derksen, 2004). Maar de psychologie bevindt zich in een positieve fase: zelfs voor de psychologen / psychotherapeuten is er hoop. Psychologische tests worden namelijk niet meer uitsluitend afgenomen volgens het aloude 'diagnose-recept' model. Ze worden steeds vaker direct met de psychologische behandeling en psychotherapie verbonden door middel van een dialoog over de bevindingen en eventuele tegenstellingen daarin (Finn, 1996; 2007).

\section{Over de waarde van psychodiagnostiek}

Het huidige zorgbeleid in de GGZ is gericht op transparantie en verantwoording; de invoering van Diagnose Behandeling Combinaties en een nadruk op stepped care en matched care nopen tot zorgvuldige psychodiagnostiek, heldere indicatiestelling en toegesneden behandeling. Daarnaast neemt het belang van psychodiagnostiek toe door de ontwikkeling van nieuwe behandelmogelijkheden voor complexe stoornissen. Die vragen immers om specifieke indicaties (zie onder meer Bateman \& Fonagy, 2006; Clarkin, Yeomans

DRS. P.T. VAN DER HEIJDEN is gezondheidszorgpsycholoog in opleiding tot klinisch psycholoog en werkt bij de Reinier van Arkel Groep te 's-Hertogenbosch. E-mail: P.T.vander.Heijden@RvAGroep.nl.

PROF. DR. J.J.L. DERKSEN is klinisch psycholoog en universitair hoofddocent psychodiagnostiek aan de Sectie Klinische Psychologie van de Radboud Universiteit Nijmegen. Tevens is hij verbonden als hoogleraar aan de Vrije Universiteit van Brussel.

DR. J.I.M. EGGER is klinisch psycholoog en universitair docent aan de Sectie Klinische Psychologie van de Radboud Universiteit Nijmegen. Hij werkt als P-opleider bij de GGZ Noord- en Midden-Limburg te Venray. 
\& Kernberg, 2006; Linehan, 1993; Young, Klosko \& Weishaar, 2003; Cormac, Jones \& Campbell, 2002). Daar waar in de jaren zeventig nauwelijks wetenschappelijk onderbouwde behandelingen beschikbaar waren voor bijvoorbeeld de borderline persoonlijkheidsstoornis, zijn er nu meerdere evidence based behandelingen mogelijk voor deze diagnose (Giesen-Bloo, 2006; Verheul et al., 2003). Behalve indicatiestelling is ook vroege onderkenning van (kwetsbaarheid voor) ernstige psychische stoornissen een doel van psychologische (test-) diagnostiek. De laatste jaren wordt steeds duidelijker dat vroege onderkenning de prognose van diverse stoornissen kan verbeteren (Marshall et al., 2005; Vollema et al., 2002).

Niet in de laatste plaats kan zorgvuldige psychodiagnostiek en de terugrapportage van de bevindingen een therapeutisch effect in zichzelf produceren. Psychologisch onderzoek en de terugrapportage van de resultaten vergroten het zelfvertrouwen van cliënten, verminderen hun demoralisatie en werken hoopgevend (Finn \& Tonsager, 1992; 1997). Dat diagnostiek en behandeling niet onafhankelijk van elkaar zijn, is trouwens iets dat bij de ervaren clinicus al langer bekend was. Zo sprak Franz Wojciechowski (1998) in Nederland tien jaar geleden al over psychopathologie, psychodiagnostiek en psychotherapie als de heilige drie-eenheid van de psychologie.

\section{Beeldvorming op verschillende niveaus}

Binnen de psychologische diagnostiek kan men een onderscheid maken tussen descriptieve diagnostiek en structurele diagnostiek (Derksen, 2004). Descriptieve diagnostiek is vooral beschrijvend, gaat vooral over gedrag, de buitenkant. Structurele diagnostiek is analyserend, gaat over de binnenkant en heeft als doel een persoonlijkheidsbeschrijving te maken op een meer verklarend niveau. Descriptieve diagnostiek wordt vooral toegepast bij enkelvoudige symptomen die plotseling zijn ontstaan. Structurele diagnostiek is juist geïndiceerd bij complexe problematiek, persoonlijkheidsstoornissen en meervoudige symptomen (Derksen, 2004; Harkness \& Lilienfield, 1997; Haynes, Leisen \& Blaine, 1997). De geïndiceerde behandeling zal juist in deze gevallen meer complex van aard zijn. Met andere woorden: bij problematiek die vaak naar de klinisch psycholoog of psychotherapeut wordt verwezen. Het psychologisch onderzoek dat hier wordt bedoeld is ongelijk aan het met semi-gestructureerde interviews of vragenlijstmethoden betrouwbaar vaststellen van DSM-categorieën. Dit laatste is vooral gangbaar in de onderzoekspraktijk, maar weinig zinvol in de klinische praktijk. De tests die in de klinische praktijk een meerwaarde bieden gaan voorbij aan de DSM-categorieën en brengen de persoonlijkheid en diens kwetsbaarheden via dimensies in beeld. De klinisch psychologisch meest gebruikte (en gevalideerde) technieken zijn wereldwijd wat betreft de zelfbeoordelingmethoden: MMPI-2 (Butcher et al., 1989; Gaham, 2006); wat betreft de cognitieve technieken: WAIS (Wechsler, 1997; Kaufman \& Lichtenberger, 1999) en wat betreft de projectieve methoden: Rorschach (Exner, 2001). 
Psychologische tests spelen een belangrijke rol bij de structurele diagnostiek. Dit is niet altijd zo geweest: het gebruik van psychologische tests was lange tijd controversieel binnen de psychotherapeutische praktijk. Er waren aanhangers, maar vooral veel felle tegenstanders. Sommige psychotherapeuten betoogden dat psychologisch testonderzoek geen rekening houdt met de individuele bijzonderheden van de cliënt. Zij vonden psychologisch onderzoek kunstmatig en irrelevant (Allport, 1929; 1937). Ook druiste de testdiagnostiek in tegen ethische gevoelens: de mens wordt gereduceerd tot scores op een aantal schalen en in een hokje geplaatst (Rogers, 1951). Verder speelden onbekendheid met statistiek hierbij een belangrijke rol, alsook de gevoelde ongerijmdheid met het zelfbeeld van de clinicus (Meehl, 1986; zie ook Ter Laak, 1995 en Ter Laak \& De Goede, 2004).

De laatste decennia wordt echter steeds duidelijker dat psychologische tests een belangrijke plaats verdienen in de diagnostiek van persoonlijkheidsstoornissen en andere complexe psychische stoornissen en disfuncties. Sterker nog, in overzichtsstudies wordt keer op keer bevestigd dat het klinische oordeel alleen onbetrouwbaar is (Dawes, Faust \& Meehl, 1989; Garb, 1998; Grove \& Meehl, 1996). Dawes, Faust \& Meehl (1989) hebben de superioriteit van statistische predictie boven klinische predictie duidelijk aangetoond. Met behulp van statistische of actuariële methoden kun je veel betere voorspellingen doen (over menselijk gedrag) dan op basis van het klinisch oordeel alleen.

In 2001 hebben Meyer en anderen een zeer uitvoerige meta-analyse gepubliceerd over de validiteit van psychologische tests. Zij onderzochten de (predictieve) validiteit van psychologische tests vergeleken met de validiteit van medische tests en beeldvormende technieken. De resultaten van 69 psychologische studies, 57 medische studies en 18 medisch-geriatrische studies werden in het onderzoek betrokken. De vier belangrijkste conclusies op grond van de gevonden resultaten zijn de volgende: (a) de validiteit van psychologische tests is sterk en overtuigend, (b) de validiteit van psychologische tests is vergelijkbaar en vaak beter dan de validiteit van veelgebruikte medische tests, (c) diverse psychologische onderzoeksmethoden bieden unieke informatie, en (d) clinici die hun uitspraken uitsluitend op klinische interviews baseren verkrijgen onvolledig inzicht in psychische en psychiatrische problematiek.

Met name de superioriteit van psychologisch onderzoek ten opzichte van geavanceerde beeldvormende technieken (zoals MRI) en liquorbepalingen leidde de Nederlandse onderzoeker Schmand recent nog tot de conclusie dat een low-tech (en low-cost) benadering, zoals psychologisch testonderzoek, veruit is te verkiezen boven een high-tech (meestal high-cost) benadering (Schmand, 2007). Hoe het ook zij, uit de meta-analyse van Meyer en anderen (2001) blijkt dat de psychologische test een zeer belangrijke plaats verdient bij de diagnostiek van psychiatrische toestandsbeelden, persoonlijkheidsstoornissen, geheugenproblematiek en intellectuele vermogens.

Hoewel in het wetenschappelijk onderzoek de controverse dus al lang is beslist in het voordeel van de statistische predictie, is de controverse over testgebruik in de klinische praktijk nog altijd actueel (vergelijk Verbraak, 
2007; Derksen, Egger \& Van der Heijden, 2008). Een integratie van testdiagnostiek in de psychotherapeutische context ligt echter veel meer voor de hand. Testonderzoek heeft bewezen voordelen als het gaat om het verzamelen van objectieve informatie en uiteindelijk gaat het er vooral om hoe je deze voordelen kunt inzetten in de therapeutische context (Finn, 2007). Finn omschrijft psychologische tests in deze zin als empathy magnifiers omdat ze helpen om onze cliënten beter te begrijpen en tegelijkertijd ook als external handholds omdat je met behulp van testscores juist meer objectief kunt kijken. In die zin bieden psychologische tests ons wat de betere supervisoren ons kunnen bieden: ze helpen ons (ideografisch) om de innerlijke wereld van de cliënt te begrijpen en tevens het nomothetisch perspectief te bewaken zodat we een neutraal zicht op de problemen behouden (Finn \& Tonsager, 1997, p. 375).

\section{Testdiagnostiek binnen de psychotherapeutische context}

Psychotherapie betekent in eerste instantie het opbouwen van een werkrelatie. Hoe kan een psychologische test daarbij helpen? Ieder psychotherapeutisch referentiekader heeft een eigen werkmodel op grond waarvan wordt bepaald wat wel of niet mogelijk is. Psychologische tests kunnen, zoals we zojuist gezien hebben, veel bruikbare informatie toevoegen. Soms worden valkuilen voor de behandeling niet direct zichtbaar in de eerste fase van het contact met een nieuwe cliënt. Met behulp van de uitslag van het psychologisch testonderzoek kan de psycholoog meer zicht krijgen op dergelijke valkuilen. Verder kan men een inschatting maken over het gewenste tempo van de behandeling, de focus en de centrale thema's en conflictgebieden (Derksen, 2004). Het psychologisch onderzoek kan bovendien licht werpen op iemands interactiestijl en belangrijkste afweermechanismen. Het kan cliënt en behandelaar behoeden voor te hoge verwachtingen. Met andere woorden: testonderzoek kan belangrijke hypotheses opleveren die vooraf richting kunnen geven aan de behandeling. Het einddoel van het diagnostische proces is het schrijven van een behandelagenda die zo concreet en dus toetsbaar mogelijk is.

Daarnaast kan psychologisch (test-) onderzoek een therapeutisch doel in zichzelf hebben: psychologisch onderzoek wordt dan toegepast in dialoog met een cliënt en is dan in wezen te beschouwen als een kortdurende psychotherapeutische interventie (Finn, 2007; Finn, 1996; Kamphuis \& Finn, 2006). Dit model dat in de jaren negentig werd ontwikkeld door de Amerikaanse psycholoog Stephen Finn heeft bekendheid gekregen onder de naam Therapeutic Assessment en blijkt een positieve bijdrage te kunnen leveren aan het therapeutisch proces: het vergroot het zelfvertrouwen van cliënten, vermindert hun demoralisatie en werkt hoopgevend (Finn \& Tonsager, 1997). Vergeleken met traditioneel psychodiagnostisch onderzoek blijkt therapeutische diagnostiek bovendien positief bij te dragen aan de kwaliteit van de therapeutische relatie en de therapietrouw (Ackerman, Hilsenroth, Baity \& Blagys, 200o). Een nabespreking van de resultaten uit het testonder- 
zoek volgens deze methode (waar de cliënt duidelijk wordt betrokken bij het psychologisch onderzoek door hem of haar ook zelf vragen te laten formuleren) kan dus een goede basis leggen voor een behandelrelatie. De cliënt voelt zich begrepen in zijn sterke en minder sterke kanten, begrijpt waar zijn klachten mee te maken kunnen hebben en kan bepaalde gedragingen en gevoelens beter plaatsen.

Bij therapeutische diagnostiek worden de vragen voor het psychologisch onderzoek in samenwerking met de cliënt geformuleerd (Finn, 2007; Kamphuis \& Finn, 2006). Naast de vraag van de verwijzer staat de vraag van de cliënt centraal. De houding van de therapeut is die van participerend observator (Finn \& Tonsager, 1997). Vervolgens worden de tests geselecteerd. Hierbij wordt in eerste instantie gekeken naar de psychometrische eigenschappen van de test en de betreffende vraagstelling. Daarnaast worden er in tweede instantie ook tests gebruikt die beter toepasbaar zijn voor de persoonlijke situatie en vragen van de cliënt. Veel gebruikte tests in deze fase zijn bijvoorbeeld de Thematic Apperception Test (TAT) of bijvoorbeeld de projectieve tekeningen. Vervolgens worden de resultaten van het gehele onderzoek zorgvuldig teruggerapporteerd aan de cliënt. Deze terugrapportage is vanzelfsprekend een van de belangrijkste aspecten van de therapeutische diagnostiek. Tijdens de gehele interventie onderhoudt de diagnosticus een empathisch contact met de cliënt en ligt de nadruk op samenwerking (Finn, 2007; Kamphuis \& Finn, 2006). Op deze wijze wordt het voor de cliënt duidelijk wat er verwacht kan worden van een behandeling, wat wel en wat niet of minder veranderbaar is en wat er van de patiënt wordt verwacht in het proces. Kortom, testdiagnostiek kan zo bijdragen aan hypothesevorming en een meer gedifferentieerde behandelagenda en wanneer de cliënt er zelf bij wordt betrokken kan het ook een proces bij de cliënt op gang brengen.

Om het gebruik van psychologische tests in de psychotherapeutische context te illustreren zullen we hieronder een casus presenteren. Bij de casus wordt gebruik gemaakt van de MMPI-2 omdat er juist met deze test veel ervaring is opgedaan in de therapeutische context (Finn, 1996; Lewak, Marks \& Nelson, 1990).

\section{Casus}

Henk Jansen (36 jaar) komt voor een intakegesprek en meldt monter dat hij psychotherapie zoekt. Hij heeft met zijn huisarts gesproken en het internet geraadpleegd en denkt hier op de juiste plaats te zijn. Hij maakt een gedecideerde indruk, lijkt het gesprek gemakkelijk te domineren en oogt niet erg somber of angstig. Hij vertelt veel vragen bij zijn eigen persoon te hebben; hij wil weten wat hij in intieme relaties niet goed doet, hoe hij daarin vooruit kan gaan en ze tot een groter succes kan maken dan tot nog toe lukte. Hij vertelt veel te piekeren over de relatie met zijn ex-vrouw en over hun twee kinderen en hij geeft aan te willen voorkomen dat de actuele relatie met zijn nieuwe vriendin hieronder zal lijden. Hij maakt de indruk gemotiveerd te zijn om naar zichzelf te kijken en het vergrootglas te 
leggen op zijn typische bijdrage aan het al of niet mislukken van een intieme relatie. Hij voert de intaker met rasse schreden door zijn levensloop en brengt hem op de hoogte van de belangrijkste feiten. Hierin valt op dat zijn vader overleed toen hij vier jaar oud was en hij als tweede in een gezin van vier kinderen met moeder alle eindjes aan elkaar moesten knopen om rond te komen. Moeder is nooit hertrouwd en kreeg geen nieuwe relatie. Over de basisschoolperiode meldt hij weinig bijzonderheden en in de adolescentie deed hij in zijn termen 'alles wat God verboden had'. Hij maakte wel het VWO af en studeerde daarna communicatiewetenschappen. Nu werkt hij als interim-manager voor een groot bedrijf. Hij trouwde op zijn 25 e jaar en kreeg twee kinderen. De relatie met zijn toenmalige vrouw verslechterde na hun eerste kind en hij kan niet zo goed aangegeven hoe dit kwam. Hij heeft het idee dat ze ieder vooral een eigen leven leidden. De echtscheiding, op initiatief van zijn ex-vrouw, was een pijnlijk proces. Uiteindelijk schikte hij zich erin. Hierna had hij diverse korte relaties die nooit langer dan een half jaar duurden en vaak door de vriendin weer werden verbroken. Nu heeft hij sinds een half jaar een nieuwe vriendin; dit gaat erg goed. Ook in zijn werk loopt alles goed. Hij heeft wel veel stress en slaapt soms slecht. De wallen onder zijn ogen lijken dit te bevestigen.

Onderzoek van de klachten wijst uit dat hij geen opvallende verstoringen van de stemming kent, geen angststoornissen en geen somatoforme stoornissen. In het contact maakt hij in lichte mate een 'cluster-B 'indruk: extravert, wat impulsief en energiek. Hij geeft aan uit te kijken naar het begin van de psychotherapie. Aan het eind van de intake wordt hem voorgesteld ook nog een psychologisch onderzoek te ondergaan met behulp van de MMPI-2, een lange vragenlijstmethode, en hij wordt uitgenodigd om op voorhand zijn vragen over dit onderzoek te stellen. Henk stemt in en zegt dat hij graag wil weten wat er nou fout loopt in intieme relaties en hoe hij dit kan voorkomen. Afname van de MMPI-2 levert een valide en dus te interpreteren profiel op (zo laten de validiteitsschalen zien). Hij heeft openhartig aan de items gewerkt, maar heeft wel de neiging psychische kwetsbaarheden wat te bagatelliseren (verhoging op schaal K). De klinische hoofdschalen laten een piek zien: schaal 4 , de vroegere psychopathische deviatieschaal. Verder zijn er geen opvallende verhogingen. Uit onderzoek met en naar schaal 4 van de MMPI-2 weten we dat deze mensen in de regel niet geïnteresseerd zijn in zelfinzicht noch in verandering van hun eigen gedrag. Ze zijn geneigd anderen als de schuldige van hun falen aan te wijzen. In relatieproblemen zijn het typisch de mensen die steeds naar de ander wijzen. Hun gedrag is vaak impulsief, narcistisch, met typische narcistische afweer (Derksen, 2007). Gevoelens worden niet beleefd maar wel vaak uitgeleefd. De kans dat mensen met deze verhoging een succesvolle psychotherapie ondergaan is minimaal.

Dit is een stevige, uit empirisch onderzoek afkomstige, boodschap voor Henk. Tijdens het feedback gesprek wordt hij niet gespaard maar respectvol geconfronteerd met deze 'nare testbevindingen'. De diagnosticus stelt zich dan weer eens naast Henk op en dan weer eens naast de test en 
spreekt feitelijk in een soort driehoeksrelatie: Henk, die beweert op zoek te zijn naar psychotherapeutische verandering, de diagnosticus die hem op zijn woord neigt te geloven en de test (spelbreker) die een andere boodschap laat zien. De boodschap van de test moeten we volgens de diagnosticus natuurlijk wel serieus opvatten en meenemen in de beslissingen. In dit gesprek blijkt dat de actuele vriendin van Henk hem ervan heeft overtuigd psychotherapie te zoeken (zij heeft dit in het verleden ook gehad) en zij dreigde ook te stoppen met de relatie indien hij dit niet zou doen. Het lukt om contact te krijgen met een andere kant van Henk. Vaak snapt hij niet waar die vrouwen het over hebben en vindt hij dat er niets met hem aan de hand is, hij werkt hard, gaat niet vreemd, drinkt niet te veel en gebruikt ook geen drugs meer (dat was wel anders tijdens zijn adolescentie). Deze aspecten komen terug in schaal 4 en eraan voorbij gaan is weinig productief en voorspelt een dreigende mislukking van de psychotherapie. Als tussenoplossing wordt er afgesproken dat er eerst enkele gesprekken volgen met zijn huidige vriendin erbij en dat er dan verder wordt bezien in hoeverre en in welk opzicht Henk vindt dat hij zou moeten veranderen. Daarop zal dan opnieuw worden teruggekomen.

\section{Tot besluit}

Diagnostici en behandelaren hebben lange tijd tegenover elkaar gestaan. Hoewel dit sociaal-maatschappelijk op vele wijzen verklaarbaar is, is het vanuit het perspectief van de wetenschap echter heel merkwaardig. Hoe kan men immers toegesneden behandelingen kiezen en starten als niet duidelijk is hoe het psychologisch disfunctioneren in elkaar steekt? Om het kort te zeggen: hoe kan er een antwoord zijn als er geen vraag is?

De psychodiagnostiek kent vele controversen. Wij willen vooral pleiten voor een integratie tussen diagnostiek en behandeling. Psychologisch onderzoek kan als (toetsbare) methode een unieke en waardevolle bijdrage leveren aan het inzicht in de cliënt en diens mogelijkheden en daarmee rechtsreeks aan het therapeutisch proces. Hopelijk wordt de kloof tussen psychologisch onderzoek en psychotherapeutische behandeling gedicht, en wordt de relatie tussen diagnosticus en behandelaar verbeterd zodat de cliënt daar uiteindelijk maximaal van kan profiteren.

\section{Literatuur}

Allport, G.W. (1929). The study of personality by the intuitive method.Journal of Abnormal and Social Psychology, 24, 14-27.

Allport, G.W.(1937). Personality: A psychological interpretation. New York: Holt. 
Ackerman, S.J., Hilsenroth, M.J., Baity, M.R., \& Blagys, M.D. (200o). Interaction of therapeutic process and alliance during psychological assessment. Journal of Personality Assessment, 75, 82-109.

Bateman, A., \& Fonagy, P. (2006). Mentalization-Based Treatment for borderline personality disorder. A practical guide. New York: Oxford University Press.

Butcher, J.N., Dahlstrom, W.G., Graham, J.R., Tellegen, A., \& Kaemmer, B. (1989). Minnesota Multiphasic Personality Inventory-2 (MMPI-2): Manual for administration and scoring. Minneapolis: University of Minnesota Press.

Clarkin, J. F., Yeomans, F., \& Kernberg, O.F. (2006). Psychotherapy for borderline personality. Focusing on object relations. American Psychiatric Publishing.

Cormac, I., Jones, C., \& Campbell, C. (2002). Cognitive behaviour therapy for schizophrenia. Cochrane.Database.Syst.Rev., CDooo524

Dawes, R.M., Faust D., \& Meehl, P.E. (1989). Clinical versus actuarial judgement. Science, 243, 1668-1674.

Derksen, J.J.L (2004). Psychologische diagnostiek. Enkele structurele en descriptieve aspecten. Nijmegen: PEN Test Publishers.

Derksen, J., De Mey, H., Sloore, H., \& Hellenbosch, G. (1993). MMPI-2: Handleiding bij afname, scoring en interpretatie. Nijmegen: PEN Test Publishers.

Derksen, J.J. L., Egger, J.I.M., \& Van der Heijden, P. (2008). Van oude misverstanden en stormen die voorbij gaan: Een reactie op Verbraak en Lima et al. Directieve Therapie, 28 , 66-74.

Derksen, J. (2007). Zij we wel narcistisch genoeg? Over het ontstaan van onze lentecultuur als gevolg van gewijzigde vroegkinderlijke condities. Nijmegen: PEN Tests Publisher.

Exner, J.E. (2001). A Rorschach workbook for the comprehensive system (5th ed.). Asheville, NC: Rorschach Workshops.

Finn, S.E., \& Tonsager, M.E. (1992). Therapeutic effects of providing MMPI-2 test feedback to college students awaiting therapy. Psychological Assessment, 4, 278-287.

Finn S.E. (1996). Manual for using the MMPI-2 as a therapeutic Intervention. Minneapolis: University of Minnesota Press.

Finn, S.E., \& Tonsager, M.E. (1997). Information-Gathering and Therapeutic Models of Assessment : Complementary Paradigms. Psychological Assessment, 9, 374-385.

Finn, S.E. (2007). In our clients shoes. Theory and Techniques of Therapeutic Assessment. Mahwah, NJ: Lawrence Erlbaum Associates.

Garb, H.N. (1998). Studying the clinician. Washington DC: American Psychological Association.

Giesen-Bloo, J., Dyck, R. van, Spinhoven, P., Tilburg, W. van, Dirksen, C., Asselt, T. van, Kremers, I., Nadort, M., \& Arntz, A. (2006). Outpatient Psychotherapy for Borderline Personality Disorder Randomized Trial of Schema-Focused Therapy vs TransferenceFocused Psychotherapy. Archives of General Psychiatry (63) 649-658.

Grove, W.M., \& Meehl, P.E. (1996). Comparative efficiency of informal (subjective, impressionistic) and formal (mechanical, algorithmic) prediction procedures: the clinical -statistical Controversy. Psychology, Public, Policy and Law, 2, 293-323.

Graham, J.R. (2006). MMPI-2: Assessing personality and psychopathology (4th edition). New York: Oxford University Press.

Harkness, A.R., \& Lilienfield, S.O. (1997). Individual difference science for treatment planning: Personality traits. Psychological Assessment, 9, 349-36o. 
Haynes, S.N., Leisen, M.B., \& Blaine, D.D. (1997). The design of individualized behavioral treatment programs using functional analytic clinical case models. Psychological Assessment, 9, 334-348.

Kamphuis, J.H., \& Finn, S.E.(2006). Therapeutische psychodiagnostiek: Het samenwerkingsmodel van Finn. In: De Ruiter, C., \& Hildebrand, M. (Red.) Handboek psychodiagnostiek: Van testmethode naar toepassing. Amsterdam: Harcourt Assessment BV.

Kaufman, A.S., \& Lichtenberger, E.O. (1999). Essentials of WAIS-III assessment. New York: Wiley.

Lewak, R.W., Marks, P.A., \& Nelson, G.E. (1990). Therapist guide to the MMPI \& MMPI-2: Providing feedback and treatment. Muncie, IN: Accelerated Development.

Linehan, M.M. (1993). Cognitive-behavioral treatment of borderline personality disorder. New York: The Guilford Press.

Marshall, M., Lewis, S., Lockwood, A., Drake, R., Jones, P., \& Croudace, T. (2005). Association between duration of untreated psychosis and outcome in cohorts of firstepisode patients: a systematic review. Archives of General Psychiatry (62) 975-983.

Meehl, P.E. (1986) Causes and effects of my disturbing little book. Journal of Personality Assessment, 50, 370-375.

Meyer, G., Finn, S., Eyde, L., Kay, G., Moreland, K., Dies, R., Eisman, E, Kubiszin, T., \& Reed, G. (2001). Psychological Testing and Psychological Assessment. A Review of Evidence and Issues. American Psychologist, 56 (2), 128-165.

Rogers, C.R. (1951). Client-centered therapy. Boston: Houghton Mifflin.

Schmand, B. (2007). Low-tech versus high-tech in de diagnostiek van neuropsychiatrische stoornissen. Antwerpen: NVN voorjaarscongres.

Ter Laak, J.J.F. (1995). Psychologische diagnostiek. Inhoudelijke en methodologische grondslagen. Lisse: Swets en Zeitlinger.

Ter Laak, J.J.F., \& Goede, M. de (2004). De controverse 'klinische versus statistische predictie' opnieuw bekeken: the state of the art. Diagnostiekwijzer, 7(1), 18-34.

Turkington, D., Kingdon, D., \& Turner, T. (2002). Effectiveness of a brief cognitivebehavioural therapy intervention in the treatment of schizophrenia. British Journal of Psychiatry, 180:523-527.

Verbraak, M. (2007). Misverstanden en mythes. Persoonlijkheidstests dragen bij tot betere resultaten van psychologische behandelingen. Directieve Therapie, 27(3), 205-207.

Verheul, R., Bosch, L.M.C. van den, Koeter, M.W.J., Ridder, M.A.J. de, Stijnen, T., \& Brink, W. van den (2003). Dialectical behaviour therapy for women with borderline personality disorder. British Journal of Psychiatry, 182, 135-140.

Vollema, M.G., Sitskoorn, M.M., Appels, M.C.M., \& Kahn, R.S. (2002). Does the Schizotypal Personality Questionnaire reflect the biological-genetic vulnerability to schizophrenia? Schizophrenia Research. Vol 54(1-2) Mar 2002, 39-45

Wechsler, D. (1997). Wechsler Adult Intelligence Scale-Third Edition. San Antonio, TX: Psychological Corporation.

Wojciechowski, F.L. (1998). Psychopathologie, psychodiagnostiek en psychotherapie: de heilige drie-eenheid in de klinische psychologie. In: C.P.F. van der Staak, J.J.L. Derksen \& C.A.L. Hoogduin (Red.). Psychodiagnostiek en indicatiestelling (pp. 22-37). Houten/ Diegem: Bohn Stafleu van Loghum.

Wood, J.M., Garb, H.N., Lilienfeld, S.O., \& Nezworski, M.T. (2002). Clinical Assessment. Annual Review of Psychology, 53, 519-543. 
Young, J.E., Klosko, J.S., \& Weishaar, M.E.(2003). Schema Therapy, a practitioner's guide. New York: Guilford. 